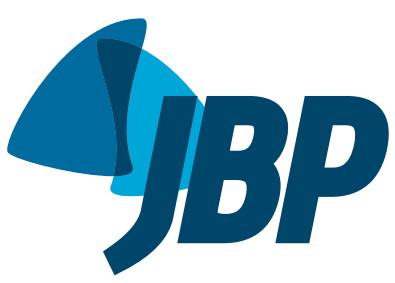

1. Programa de Controle da Tuberculose do Município de Carapicuíba, Carapicuíba (SP) Brasil.

2. Universidade Federal de São Paulo, São Paulo (SP) Brasil.

3. Centro Universitário São Camilo de São Paulo, São Paulo (SP) Brasil.

Submitted: 21 January 2016.

Accepted: 1 September 2016.

Study carried out under the auspices of the Programa de Controle da Tuberculose do Município de Carapicuíba, Carapicuíba (SP) Brasil.

\section{Tuberculosis recurrence in a priority city in the state of São Paulo, Brazil}

\author{
Amadeu Antonio Vieira ${ }^{1,2}$, Danila Torres Leite ${ }^{3}$, Solange Adreoni²
}

\begin{abstract}
Objective: To describe cases of tuberculosis recurrence (TBR), stratified by temporal classification (early or late TBR), and to identify possible predictors of such recurrence. Methods: This was an analytical retrospective observational epidemiological study involving a cohort of 963 new cases of pulmonary tuberculosis, reported and treated via the Tuberculosis Control Program in the city of Carapicuíba, Brazil. The study period was from 2000 to 2010. All of the pulmonary tuberculosis patients who successfully completed the treatment (with or without confirmation of cure) were selected and followed until December 31, 2012. Results: Of the 963 cases, TBR occurred in 47 (4.88\%). The mean time between the first and second tuberculosis episodes was 36.12 months. Of the 47 TBR cases, 16 (34.04\%) occurred within the first 18 months after the completion of the initial treatment (early TBR) and 31 (65.96\%) occurred thereafter (late TBR). There were statistically significant differences between the early and late TBR groups only regarding level of education ( $\leq 3$ vs. $>3$ years of schooling; $p<0.004$ ) and weight gain at completion of the initial treatment $(1.78 \mathrm{~kg}$ vs. $5.31 \mathrm{~kg} ; \mathrm{p}<0.045)$-not regarding any of the other variables studied. Conclusions: A low level of education might translate to poor treatment adherence, which impedes the killing of bacilli and facilitates their survival in a latent state, making it appear as if the treatment was effective. Minimal or no weight gain at completion of the initial treatment might be a reliable biomarker to be used by health care facilities that provide tuberculosis treatment.
\end{abstract}

Keywords: Recurrence; Tuberculosis; Risk factors.

\section{INTRODUCTION}

Tuberculosis, which is considered to be a curable disease, is one of the oldest diseases known to mankind. Shortterm treatment regimens combining rifampin, isoniazid, pyrazinamide, and ethambutol have an efficacy of nearly $100 \%$ provided that the drugs are administered in the correct doses and for the appropriate amount of time in drug-susceptible patients; however, tuberculosis remains a serious public health problem in the 21 st century. ${ }^{(1-4)}$ The World Health Organization estimates that over 9 million people have had tuberculosis; of those, 1.5 million have died, whereas 300,000 have developed the disease again after having been treated and considered cured, ${ }^{(3)}$ constituting cases of tuberculosis recurrence (TBR).

Studies have shown that the risk of TBR is higher in previously treated tuberculosis patients than in the general population, being up to four times higher in the former than in the latter depending on the epidemiological profile of the disease at the study site. ${ }^{(5,6)}$ A major concern for tuberculosis control programs (TCPs), TBR is overlooked and understudied by researchers and health authorities alike. TBR rates vary widely, being $0.4 \%$ in patients receiving directly observed treatment, short-course (DOTS) and over $30 \%$ in appropriately treated patients receiving self-administered treatment. ${ }^{(7-9)}$
TBR is due to endogenous reactivation (also known as relapse), caused by the same bacterial strain that caused the first episode of tuberculosis (probably because of bacillary persistence), or exogenous infection (also known as reinfection) with a new strain of Mycobacterium tuberculosis. Although there is no clinical difference between relapse and reinfection, they can be differentiated by using molecular biology techniques, which are usually unavailable in routine clinical practice. . $^{(5,8,10-12)}$ According to the British Medical Research Council, $91 \%$ of relapses occur before post-discharge month 12 , and a recent review of the latest clinical trials of new tuberculosis treatment regimens showed that $94 \%$ of relapses occurred within the first 18 months after treatment completion. ${ }^{(13)}$ TBR can be classified as early TBR or late TBR; the former is defined as TBR occurring within the first 18 months after treatment completion, whereas the latter is defined as TBR occurring thereafter. $(6,8,12,14)$

A better knowledge and understanding of TBR will improve the surveillance and follow-up of tuberculosis patients discharged from treatment, thus improving disease control and contributing to breaking the chain of transmission. The objective of the present study was to describe cases of early and late TBR in a cohort of patients treated via a municipal TCP and to identify possible predictors of such recurrence. 


\section{METHODS}

\section{Characterization of the study site}

The present study was conducted in the city of Carapicuíba, Brazil, a bedroom community in the greater metropolitan area of São Paulo. The latest census showed that Carapicuíba had a population of 369,908 inhabitants, being one of the most densely populated cities in the country (i.e., 10,576 people/ $\mathrm{km}^{2}$ ). In 1995, the Programa Nacional de Controle da Tuberculose (PNCT, Brazilian National Tuberculosis Control Program) identified the city of Carapicuíba as a priority because of its high burden of tuberculosis, with a mean incidence of 41.77 cases per 100,000 population in the last 5 years. ${ }^{(15)}$ The local TCP was launched in the 1990s and, on the basis of epidemiological criteria, has been considered a priority by the Brazilian National Ministry of Health since then. In 2004, the DOTS strategy was implemented in all primary care clinics in the city via the local TCP, the decentralization of diagnosis being achieved by actively searching for patients with respiratory symptoms and collecting samples for smear microscopy at all public health care facilities. A rapid molecular biology-based assay has recently been implemented.

\section{Study design}

This was an analytical retrospective observational epidemiological study involving a cohort of new cases of tuberculosis, reported and treated via the TCP in the city of Carapicuíba. The study period was from 2000 to 2010. All of the pulmonary tuberculosis (PTB) patients who successfully completed the treatment (with or without confirmation of cure, as defined by the PNCT) were selected and followed until December 31, 2012 (Figure 1). The inclusion, exclusion, and follow-up criteria were those used in a larger study approved by the Research Ethics Committee of the Federal University of São Paulo (Protocol no. 0690/11).(15) TBR (the dependent variable) was defined as a second episode of tuberculosis after completion of the initial treatment, being classified as early or late TBR. Early TBR was defined as PTB occurring within the first 18 months after treatment completion. Late TBR was

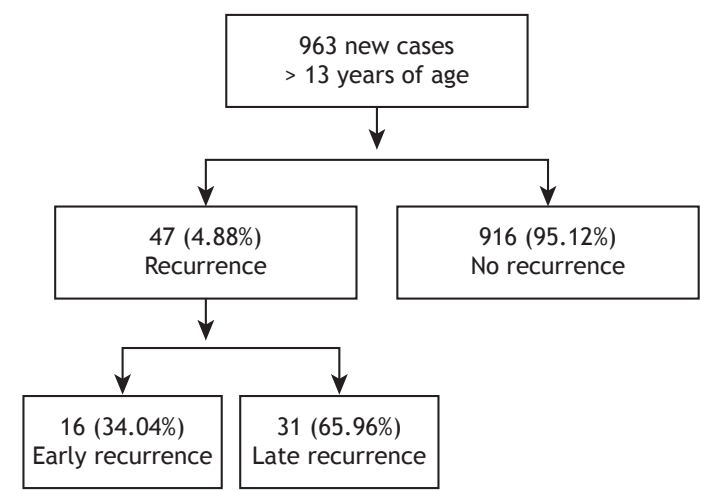

Figure 1. Flowchart of pulmonary tuberculosis cases in the city of Carapicuíba, Brazil, in the 2000-2012 period. defined as PTB occurring more than 18 months after treatment completion.

\section{Data source and variables analyzed}

Data were collected from the São Paulo State Epidemiological Surveillance Tuberculosis System (Epi-TB database) and the Online Epidemiological Surveillance Tuberculosis System (TBweb database) for the 20002005 and 2006-2010 periods, respectively. All data collected from the TBweb database were collected in real time. After identification of the medical record numbers, patient medical records were retrieved for data collection. Data were collected with the use of questionnaires developed specifically for the present study, being subsequently entered into an Epi Info 3.3 database. Double data entry and the Epi Info "data compare" tool were used in order to verify data consistency and eliminate typographical errors.

For the first episode of PTB, the following independent variables were analyzed: sociodemographic variables (gender, age, level of education, occupation-in accordance with the Brazilian Institute of Geography and Statistics-and household contact); comorbidities/ unhealthy habits (diabetes mellitus, HIV infection, alcoholism, smoking, and drug addiction); signs and symptoms (time from onset of signs and symptoms to treatment, cough, fever, and sweating); clinical variables (active PTB, bilateral pulmonary involvement, and pulmonary cavitation); health and diagnostic equipment (place of treatment and type of facility); and treatment-related variables (number of doses taken during self-administered treatment, number of doses taken during DOTS, number of doses missed during DOTS, weight gain-in $\mathrm{kg}$-in the attack phase, weight gain-in $\mathrm{kg}$-at discharge from treatment, negative smear results in the attack phase, adverse events during treatment, and home contact with active tuberculosis during follow-up).

\section{Statistical analysis}

A frequency distribution table showing absolute and relative values was constructed to describe the characteristics of TBR cases. In order to determine the association between independent variables and the dependent variable (early or late TBR), the chi-square test was used, Yates' correction or Fisher's exact test being used when necessary; for risk assessment, prevalence ratios (PRs) were used, with a $95 \% \mathrm{CI}$ and a significance level of $p \leq 0.05$; for continuous variables related to early or late TBR (independent groups), the Student's t-test (Levene's test) or the Mann-Whitney (Kruskal-Wallis) test was used, with a significance level of $p \leq 0.05$. All statistical analyses were performed with the IBM SPSS Statistics software package, version 20 (IBM Corporation, Armonk, NY, USA).

\section{RESULTS}

By the end of the follow-up period, TBR had occurred in $47(4.88 \%)$ of the 963 PTB patients in our cohort; 
in half of the cases, TBR occurred within 34 months after treatment completion. The mean time between treatment and TBR was 36.12 months (range, 2.5298.04 months). Of the 47 cases of TBR, 7 (14.89\%) occurred within the first 6 months after treatment completion, whereas $13(27.66 \%)$ and 16 (34.04\%) occurred within the first 12 and 18 months, respectively, and were therefore considered to be cases of recent TBR; the remaining 31 TBR cases $(65.96 \%)$ occurred more than 18 months after treatment completion and were therefore considered to be cases of late TBR (Figure 2).

Of the 47 patients in whom there was TBR, 35 (74.47\%) were male, and the mean age was 32.77 years. Approximately $45 \%$ had had $\geq 8$ years of schooling. Most of the patients were currently employed $(70.22 \%)$ and had home contacts $(93.62 \%)$. The most prevalent comorbidity was diabetes mellitus (in $14.89 \%$ ), and the most prevalent unhealthy habit was smoking (in $44.68 \%$ ). Cough was reported by most of the patients $(97.87 \%)$. With regard to the clinical variables, $80.85 \%$ of the patients had active tuberculosis (positive smear results at diagnosis), $63.83 \%$ had bilateral pulmonary involvement, and $57.45 \%$ had imaging findings suggestive of pulmonary parenchymal cavitation; only $8.51 \%$ had been diagnosed at private facilities, and slightly more than half had been diagnosed in an emergency room or hospital.

The mean number of doses taken during self-administered treatment was 92.27 , and the mean number of doses taken during DOTS was 84.73; although $46.81 \%$ of the patients experienced adverse events during the initial treatment, only 1 (4.54\%) experienced a major adverse event (drug hepatotoxicity), with no need to change the standard regimen. There was weight gain at the end of the attack phase in $74.47 \%$ and at discharge from treatment in $82.98 \%$. In addition, approximately $15 \%$ had household contacts with active tuberculosis during treatment.

A bivariate analysis of the association between categorical variables and early or late TBR (Table 1) showed that the level of education was the only significant variable ( $p \leq 0.05)$; that is, a lower level of education translated to a greater association with early TBR (PR $=1.70$ for up to 3 years of schooling; PR $=1.59$ for $4-7$ years of schooling). None of the other categorical variables were found to have statistical significance. A bivariate analysis of the association between quantitative variables and early or late TBR (Table 2) showed that weight gain (in $\mathrm{kg}$ ) at discharge from treatment was the only significant variable, the mean weight gain being $1.78 \mathrm{~kg}$ for the early TBR group and $5.31 \mathrm{~kg}$ for the late TBR group.

\section{DISCUSSION}

The proportions of TBR cases vary widely across studies, ranging from $0.4 \%$ to $61.7 \%(4,6,9,16-20)$; the incidence of TBR in the present study is consistent with that reported in locations where there are well-structured TCPs (i.e., 5-6\%). ${ }^{(21,22)}$ The incidence of TBR in the present study is also consistent with that reported in locations where the reported incidence of tuberculosis is low, such as North America and Australia, ${ }^{(16,18)}$ moderate, such as Brazil and Spain ${ }^{(19,20)}$ and high, such as South Africa and Ethiopia, ${ }^{(4,20)}$ regardless of heterogeneity and tuberculosis burden. $(3,4,6,12,16-20)$

Cases of relapse occur toward the end of the treatment period, primarily between months 6 and

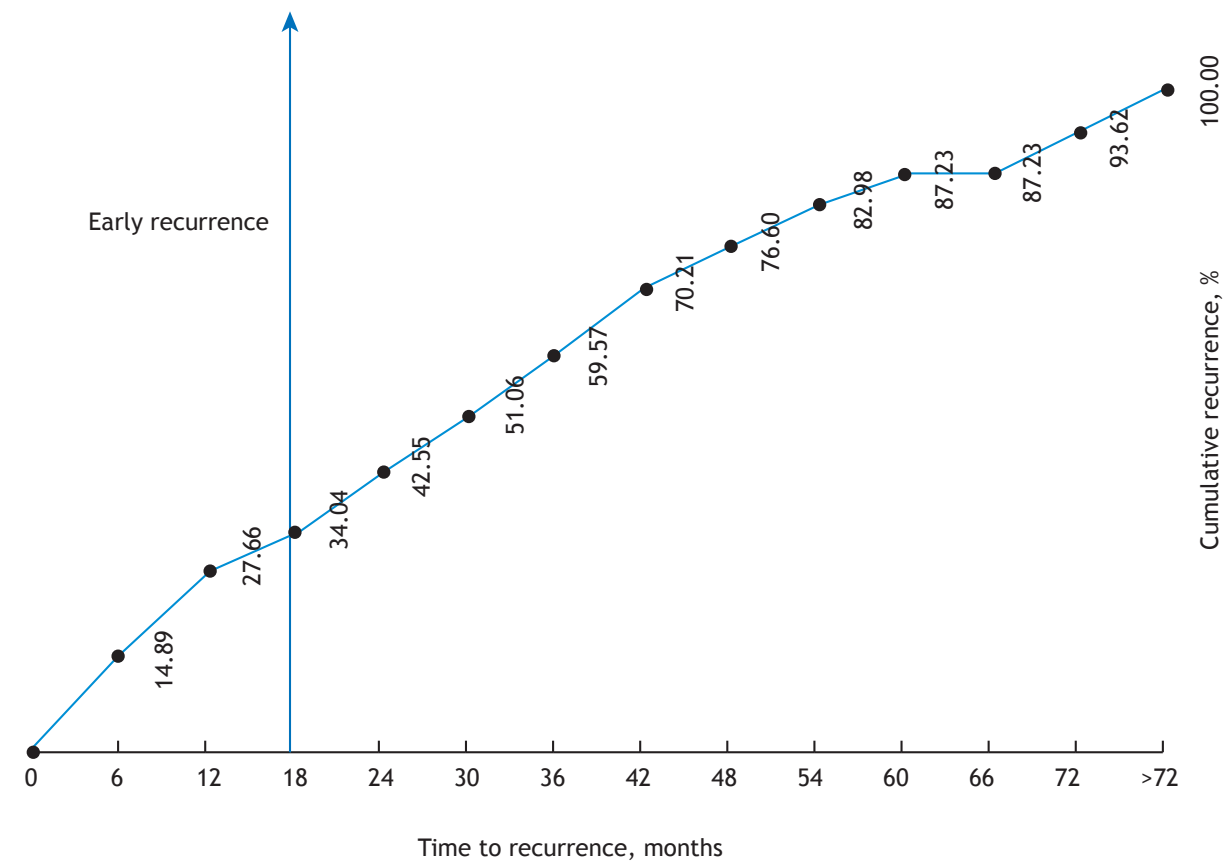

Figure 2. Cumulative recurrence of pulmonary tuberculosis during follow-up (in months) in the city of Carapicuíba, Brazil, in the 2000-2012 period. 
Table 1. Frequency distribution and prevalence ratio, by type of pulmonary tuberculosis recurrence, in the city of Carapicuíba, Brazil, in the $2000-2012$ period.

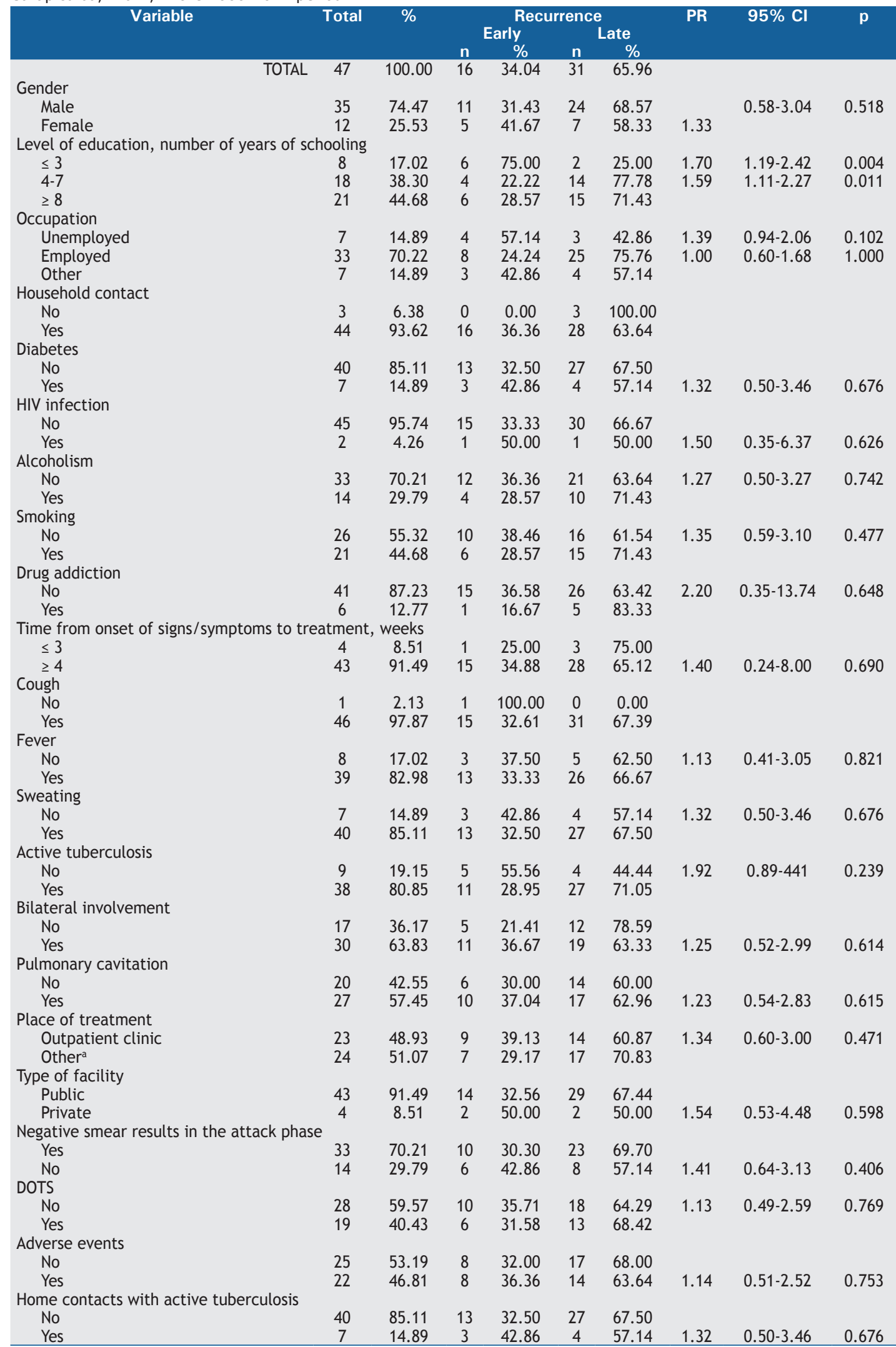

PR: prevalence ratio; and DOTS: directly observed treatment, short-course. ${ }^{a}$ Emergency room or hospital. 
Table 2. Variables, by recurrence type, in the city of Carapicuíba, Brazil, in the 2000-2012 period.

\begin{tabular}{|c|c|c|c|c|}
\hline \multirow[t]{2}{*}{ Variable } & \multicolumn{2}{|c|}{ Recurrence } & \multirow[t]{2}{*}{ Difference $^{a}$} & \multirow[t]{2}{*}{$\mathbf{p}$} \\
\hline & $\begin{array}{l}\text { Early } \\
\text { Mean }\end{array}$ & $\begin{array}{l}\text { Late } \\
\text { Mean }\end{array}$ & & \\
\hline Age, years & 37.94 & 30.10 & 7.84 & 0.096 \\
\hline Doses taken during SAT, $\mathrm{n}$ & 99.57 & 88.50 & 11.07 & 0.667 \\
\hline Doses taken during DOTS, $\mathrm{n}$ & 85.00 & 84.89 & 0.11 & 0.419 \\
\hline Doses missed during DOTS, $\mathrm{n}$ & 11.22 & 2.19 & 9.03 & 0.119 \\
\hline Weight gain within 60 days after treatment initiation, $\mathrm{kg}$ & 1.11 & 3.39 & 2.27 & 0.108 \\
\hline Weight gain at treatment completion, $\mathrm{kg}$ & 1.78 & 5.31 & 3.53 & 0.045 \\
\hline
\end{tabular}

SAT: self-administered treatment; and DOTS: directly observed treatment, short-course. aExpressed as absolute values.

$12^{(13,14)}$; therefore, in phase III clinical trials examining the efficacy of new drugs or treatment regimens for tuberculosis, patients are followed until 18 months after discharge from treatment (cure). ${ }^{(13)}$ Relapse, which is also known as endogenous reactivation, is caused by the same bacterial strain that caused the first episode of tuberculosis (probably because of bacillary persistence). The term persistence refers to the ability of bacilli to survive dormant within alveolar macrophages or in caseous areas even when they are sensitive to antituberculosis drugs and when bactericidal concentrations of chemotherapeutic agents are adequate during treatment. When conditions are favorable, these bacilli become metabolically active and multiply. When they multiply during treatment, they are completely eliminated by chemotherapy; however, if they resume their metabolic activity after discharge from treatment, TBR occurs. ${ }^{(13,23-26)}$

Several studies ${ }^{(8,12,19,26-30)}$ have shown that TBR resulting from exogenous reinfection occurs long after treatment completion, more consistently over time and predominantly in locations where the burden of tuberculosis is moderate or high, because the chain of transmission is active. This was confirmed experimentally in a laboratory setting, ${ }^{(21)}$ cured animals having subsequently developed a transient specific antigenic immune response that decreased over time. This transient resistance appears to prevent hematogenous spread of new bacilli and, consequently, a second episode of tuberculosis caused by early exogenous infection.

In the present study, a low level of education was found to be a risk factor for early TBR, possibly interfering with treatment adherence. The number of doses taken during self-administered treatment was higher in the early TBR group than in the late TBR group, although the difference was not statistically significant; however, it was impossible to determine the exact number of doses taken during treatment. It can be hypothesized that treatment adherence was lower in the early TBR group, a hypothesis that supports the recommendation of the World Health Organization and several groups of authors that DOTS be used. $(3,14,16,19,24)$ Tuberculosis is a disease that has long been associated with poverty and low socioeconomic development, as indirectly measured by little or no schooling $(9,10,12,31)$; therefore, poverty can be associated with poor health status, or the latter can affect work and working conditions or limit job opportunities. This can also have an impact on treatment adherence, ${ }^{(14,16,19,24)}$ thus explaining the aforementioned biological mechanism for bacillary persistence in cases of TBR, a mechanism that has been confirmed in other studies. ${ }^{(32,33)}$

In the present study, early TBR was found to be associated with reduced weight gain at discharge from treatment, a finding that suggests greater activation of tuberculosis-related chemical mediators, slower normalization of those mediators, or a combination of the two. In a clinical trial, ${ }^{(34)}$ it was found that, among individuals who were underweight at diagnosis, weight gain of $5 \%$ or less during treatment was associated with an increased risk of TBR. An association between weight loss and TBR has been found in observational studies $^{(35-37)}$ and in laboratory animal studies, ${ }^{(23,33)}$ as well as having been found in an operational study conducted in Bangladesh. ${ }^{(38)}$ Weight loss and malnutrition are common in patients with tuberculosis; however, it is difficult to distinguish between cause and effect. The fact that TNF- $a$ is released into the bloodstream of tuberculosis patients by sensitized phagocytic cells and that TNF- $a$ is related to weight loss and cachexia can partially explain why weight loss is a common complaint in patients with tuberculosis. ${ }^{(32-36)}$ In addition to TNF- $a$, the concentrations of IL-1, IL-6, IFN- $\gamma$, and prostaglandins are altered in individuals with cachexia, emphasizing the role of chronic diseases, such as tuberculosis, in the process of weight loss. ${ }^{(37)}$

Potential limitations of the present study include recall and information biases. It is possible that the answers that the patients themselves or their legal guardians gave to questions regarding some of the exposure variables, such as time from onset of signs and symptoms to treatment, cough, fever, and sweating, resulted in recall bias. It is also possible that their answers to questions regarding comorbidities and unhealthy habits, such as alcoholism, smoking, and drug addiction, resulted in information bias. Therefore, there is a possibility that these two potential biases affected the significance of the aforementioned variables. Another limitation is that it was impossible to control for confounding variables because of the small number of TBR cases during the follow-up period, a stratified or multivariate statistical analysis of early and late TBR therefore being impossible. Yet another limitation 
is that it was impossible to distinguish between TBR resulting from endogenous reactivation and TBR resulting from exogenous reinfection. Molecular biology methods are not routinely used in Brazil as they are in countries such as the United States. However, this does not invalidate the results of the present study. One strength of the present study is that it was a retrospective observational study of secondary data from a municipal TCP, such data being much more representative of daily clinical and operational practices than are those from controlled clinical trials.

In summary, the present study showed that TBR cases occurring within the first 18 months after treatment completion (early TBR cases) were more common than late TBR cases, the occurrence of which increased consistently thereafter, a finding that is consistent with the literature. A low level of education might translate to poor treatment adherence, which impedes the elimination of bacilli and facilitates their survival in a latent state, making it appear as if the treatment was effective, as observed in the present study. One strategy to reduce early TBR, as well as for cases in which there is minimal or no weight gain at treatment completion, is to prolong treatment on the basis of the number of doses missed during DOTS, as recommended by the PNCT. Although minimal or no weight gain at treatment completion might be a reliable biomarker to be used by health care facilities that provide tuberculosis treatment, further studies of TBR are needed in order to confirm that.

\section{REFERENCES}

1. Dooley KE, Lahlou O, Ghali I, Knudsen J, Elmessaoudi MD, Cherkaoui I, et al. Risk factors for tuberculosis treatment failure, default or relapse and outcomes of retreatment in Morocco. BMC Public Health. 2011;11:140. https://doi.org/10.1186/1471-2458-11-140

2. Vynnycky E Borgdorff MW, Leung CC, Tam CM, Fine PE. Limited impact of tuberculosis control in Hong Kong: attributable to high risks of reactivation disease. Epidemiol Infect. 2008;136(7):943-52. https:// doi.org/10.1017/S0950268807008552

3. World Health Organization. Global tuberculosis report 2014. Geneva: World Health Organization; 2014

4. Datiko DG, Lindtjørn B. Tuberculosis recurrence in smear-positive patients cured under DOTS in southern Ethiopia: retrospective cohort study. BMC Public Health. 2009;9:348. https://doi.org/10.1186/14712458-9-348

5. Cacho J, Pérez Meixeira A, Cano I, Soria T, Ramos Martos A Sánchez Concheiro M, et al. Recurrent tuberculosis from 1992 to 2004 in a metropolitan area. Eur Respir J. 2007;30(2):333-7. https:// doi.org/10.1183/09031936.00005107

6. Millet JP, Orcau A, de Olalla PG, Casals M, Rius C, Caylà JA Tuberculosis recurrence and its associated risk factors among successfully treated patients. J Epidemiol Community Health 2009;63(10):799-804. https://doi.org/10.1136/jech.2008.077560

7. Chaisson RE, Churchyard GJ. Recurrent tuberculosis: relapse, reinfection, and HIV. J Infect Dis. 2010; 201(5): 653-5. https://doi. org/10.1086/650531

8. Pascopella L, Deriemer K, Watt JP, Flood JM. When tuberculosis comes back: who develops recurrent tuberculosis in California? PLoS One. 2011;6(11):e26541. https://doi.org/10.1371/journal. pone.0026541

9. Maehira Y, Chowdhury El, Reza M, Drahozal R, Gayen TK, Masud I, et al. Factors associated with relapse into drug use among male and female attendees of a three-month drug detoxification-rehabilitation programme in Dhaka, Bangladesh: a prospective cohort study. Harm Reduc J. 2013;10:14. https://doi.org/10.1186/1477-7517-10-14

10. de Peralta YT, Forment AS, Sánchez EB, Mulet EC, Smith NN Relapse and associated risk factors in patients with tuberculosis in Santiago de Cuba (2002-2008) [Article in Spanish]. MEDISAN. 2010;14(8):1045-53

11. Gomes MG, Aguas R, Lopes JS, Nunes MC, Rebelo C, Rodrigues $P$, et al. How host heterogeneity governs tuberculosis reinfection? Proc Biol Sci. 2012;279(1737):2473-8. https://doi.org/10.1098/ rspb.2011.2712

12. Millet JP, Shaw E, Orcau A, Casals M, Miró JM, Caylà JA, et al. Tuberculosis recurrence after completion treatment in a European city: reinfection or relapse? PLoS One. 2013;8(6):e64898. https://doi. org/10.1371/journal.pone.0064898

13. Johnson JL, Thiel BA. Time until relapse in tuberculosis treatment trials: implication for phase 3 trial design. Am J Respir Crit Care Med. 2012;186(5):464. https://doi.org/10.1164/ajrccm.186.5.464

14. Selassie AW, Pozsik C, Wilson D, Ferguson PL. Why pulmonary tuberculosis recurs: a population-based epidemiological study Ann Epidemiol. 2005;15(7): 519-25. https://doi.org/10.1016/j. annepidem.2005.03.002
15. Vieira $A A$. Fatores associados à recorrência de tuberculose e óbito pós-tratamento no município de Carapicuíba. [thesis]. São Paulo: Escola Paulista de Medicina, Universidade Federal de São Paulo; 2015.

16. Dobler CC, Marks GB, Simpson SE, Crawford AB. Recurrence of tuberculosis at a Sidney chest clinic between 1994 and 2006: reactivation or reinfection? Med J Aust. 2008;188(3):153-5.

17. Dobler CC, Crawford AB, Jelfs PJ, Gilbert GL, Marks GB Recurrence of tuberculosis in a low-incidence setting. Eur Respir J. 2009;33(1):160-7. https://doi.org/10.1183/09031936.00104108

18. Schneider E, Laserson KF, Wells CD, Moore M. Tuberculosis along the United States-Mexico border, 1993-2001. Rev Panam Salud Publica. 2004;16(1): 23-33. https://doi.org/10.1590/S102049892004000700004

19. Picon PD, Bassanesi SL, Caramori ML, Ferreira RL, Jarczewski CA, Vieira PR. Risk factors for recurrence of tuberculosis. J Bras Pneumol. 2007;33(5):572-8. https://doi.org/10.1590/S180637132007000500013

20. Middelkoop K, Bekker LG, Shashkina E, Kreiswirth B, Wood R Retreatment tuberculosis in a South African community: the role of re-infection, HIV and antiretroviral treatment. Int J Tuberc Lung Dis. 2012;16(11): 1510-6. https://doi.org/10.5588/ijtld.12.0049

21. Woolhiser LK, Hoff DR, Marietta KS, Orme IM, Lenaerts AJ. Testing of experimental compounds in a relapse model of tuberculosis using granulocyte-macrophage colony-stimulating factor gene-disrupted in mice. Antimicrob Agents Chemother. 2009;53(1):306-8. https://doi. org/10.1128/AAC.01346-07

22. Ruffino-Neto A. Recurrence of tuberculosis. J Bras Pneumol. 2007;33(5): xxvii-xxvviii.

23. Pettit AC, Kaltenbach LA, Maruri F, Cummins J, Smith TR, Warkentin $\mathrm{JV}$, et al. Chronic lung disease and HIV infection are risk factors for recurrent tuberculosis in low-incidence setting. Int J Tuberc Lung Dis. 2011;15(7):906-11. https://doi.org/10.5588/ijtld.10.0448

24. Chang KC, Leung CC, Yew WW, Chan SL, Tam CM. Dosing schedules of 6-month regimens and relapse for pulmonary tuberculosis. Am J Respir Crit Care Med. 2006;174(10):1153-8. https://doi.org/10.1164/ rccm.200605-6370C

25. Harries AD, Hargreaves NJ, Kwanjana JH, Salaniponi FM. Relapse and recurrent tuberculosis in the context of a national tuberculosis control programme. Trans R Soc Trop Med Hyg. 2000;94(3):247-9. https://doi.org/10.1016/S0035-9203(00)90306-7

26. Bandera A, Gori A, Catozzi L, Degli Esposti A, Marchetti G, Molteni $\mathrm{C}$, et al. Molecular epidemiology study of exogenous reinfection in an area with a low incidence of tuberculosis. J Clin Microbiol 2001;39(6):2213-8. https://doi.org/10.1128/JCM.39.6.2213 2218.2001

27. Lambert ML, Hasker E, Van Deun A, Roberfroid D, Boelaert M, Van der Stuyft $P$. Recurrence in tuberculosis: relapse or reinfection? Lancet Infect Dis. 2003;3(5):282-7. https://doi.org/10.1016/S14733099(03)00607-8

28. Jasmer RM, Bozeman L, Schwartzman K, Cave MD, Saukkonen JJ, Metchock B, et al. Recurrent tuberculosis in the United States and Canada: relapse or reinfection? Am J Respir Crit Care Med. 
2004;170(12):1360-6. https://doi.org/10.1164/rccm.200408-10810C

29. Glynn JR, Murray J, Bester A, Nelson G, Shearer S, Sonnenberg P. High rates of recurrence in HIV-infected and HIV-uninfected patients with tuberculosis. J Infect Dis. 2010; 201(5):704-11. https://doi. org/10.1086/650529

30. Kim L, Moonan PK, Yelk Woodruff RS, Kammerer JS, Haddad MB. Epidemiology of recurrent tuberculosis in the United States, 1993-2010. Int J Tuberc Lung Dis. 2013;17(3):357-60. https://doi. org/10.5588/ijtld.12.0640

31. Geraldes Santos Mde L, Figueiredo Vendramini SH, Gazetta CE, Cruz Oliveira SA, Scatena Villa TC. Poverty: socioeconomic characterization at tuberculosis. Rev Lat Am Enfermagem. 2007;15 Spec No:762-7.

32. Campos H. Da infecção pelo M. tuberculosis a doença tuberculosa. Bol Pneum Sanit. 1998;6(2):7-34

33. Wayne LG, Sohaskey CD. Nonreplicating persistence of Mycobacterium tuberculosis. Annu Rev Microbiol. 2001;55:139-63. https://doi.org/10.1146/annurev.micro.55.1.139
34. Khan A, Sterling TR, Reves R, Vernon A, Horsburgh CR. Lack of weight gain and relapse risk in a large tuberculosis treatment trial. Am J Respir Crit Care Med. 2006;174(3): 344-8. https://doi.org/10.1164/ rccm.200511-18340C

35. Sita-Lumsden A, Lapthorn G, Swaminathan R, Milburn HJ, Reactivation of tuberculosis and vitamin D deficiency: the contribution of diet and exposure to sunlight. Thorax. 2007;62(11):1003-7. https:// doi.org/10.1136/thx.2006.070060

36. Rohini K, Surekha B, Srikumar PS, Jyoti S, Mahesh Kumar A. Body weight gain in pulmonary tuberculosis during chemotherapy. Int $J$ Collab Res Intern Med Public Health. 2013;5(4):247-54.

37. Associação Brasileira de Cuidados Paliativos. Consenso brasileiro de caquexia, anorexia em cuidados paliativos. Rev Bras Cuid Paliativos. 2011;3(Suppl 1):4-42.

38. Aung KJ, Declercq E, Ali MA, Naha S, Datta Roy SC, Taleb MA, et al. Extension of the intensive phase reduces relapse but not failure in a regimen with rifampicin throughout. Int J Tuberc Lung Dis. 2012:16(4):455-61. https://doi.org/10.5588/iitld.11.0216 